\title{
Simulation and Measurement of Air Movement Inside a Standard Veterinary Operating Room Produced by a Double-Equal Strength Diffuser
}

\author{
Florin DOMNITA ${ }^{1 *}$, Marius FETEA ${ }^{1}$, Dana-Adriana ILUTIU-VARVARA ${ }^{1}$, Peter KAPALO ${ }^{2}$ \\ ${ }^{1}$ Faculty of Building Services, Technical University of Cluj-Napoca, 128-130 21 Decembrie 1989 \\ Boulevard, 400604, Cluj-Napoca, Romania \\ ${ }^{2}$ Faculty of Civil Engineering, Institute of Architectural Engineering, Technical University of Kosice, 4 \\ Vysokoskolska Street, 04200 Kosice, Slovakia \\ *Corresponding author: florin.domnita@insta.utcluj.ro
}

Bulletin UASVM Veterinary Medicine 73(1) / 2016,

Print ISSN 1843-5270; Electronic ISSN 1843-5378

DOI:10.15835/buasvmcn-vm: 11765

\begin{abstract}
The main purpose of air diffusers is to achieve ventilation effect by obtaining a proper distribution of the introduced air jet. Even more in the case of veterinary operating rooms, it is necessary to use air diffusers that allow the introduction of large volumes of air without exceeding admissible indoor air velocities in the occupied zone.

The paper presents a device with double-equal strength diffuser for introducing conditioned air inside a standard veterinary operating. There are presented the measurements that were performed in order to establish the air velocity field generated by the diffuser. It is also shown the computational air movement simulation produced by this device in two models of veterinary operating room.

The diffuser allows the distribution of large quantities of blow-in air with low velocities, recommended for using in locations with a high required air exchange. The simulations provides an overview of velocity and pressure fields generated by the double-equal strength diffuser for spatial distribution of air, within two sitemodels of veterinary operating room. Simulation results are displayed graphically by presenting the distribution of air velocity vectors in different planes of intersection with the considered site-model configuration.

Analyzing the results of simulations performed on the two models, together with the measurements made in the laboratory on the double exponential profile diffuser, it can be concluded that the device provides good solutions in terms of air flow inside the operating room. Thus, is obtained a hybrid airflow cleanroom, recommended in recent years in scientific literature to use in veterinary operating rooms.
\end{abstract}

Keywords: air, diffuser, movement, strength, velocity

\section{INTRODUCTION}

In recent years, the human activities tend more towards operations less physically demanding that requires the reconsideration of ventilation and air conditioning systems design. Under these conditions, the comfort air velocity must have lower values, which involves special distribution measures in order to achieve a strictly controlled indoor air movement.
Since air distribution in mechanically ventilated rooms is determined for the most part (about $90 \%$ ) of air jets, it means that the current streams generated by air jets must provide appropriate ventilation effect primarily in the occupied zone (Popovici et al., 2010). The most ventilation solutions of hospital operating rooms for both humans and animals, recommended the use of large inlet air devices to enable the introduction of 
high rates of airflow with low primary air velocities values (Domnita, 2003). In this way it increases also the phenomenon of indoor air induction into the inlet air jet main stream.

The use of laminar airflow ventilation systems has been advocated in human medicine and also adopted in veterinary medicine. Laminar airflow ventilation systems provide vertical layers of air movement in the operating room such that the flow is highest directly over the surgical site, limiting the introduction of particles from the environment and personnel. Lidwell et al. (1987) demonstrated a significant reduction in the rate of surgical site infections in veterinary hospitals after the introduction of laminar airflow systems.

In real situations, the current lines of air jets are more or less influenced by other fields of air pressure created in natural or mechanical way by infiltrated or accidentally appeared air currents, by the presence of natural obstacles which are due to the presence of machinery, furniture, building components or the occupants themselves. Compare with this, both in theoretical studies and researches on experimental stands, it creates the conditions for free airflow evolution. It is considered that the air jet current streams are arising from the pole of the jet. Also, it must be taken measures to stabilize the airflow in the ventilation duct in the upstream section from the inlet device.

Memarzadeh (2002) shows that ventilation systems that provide laminar flow conditions are the best choice, although some care needs to be taken in their design. An air velocity at least of $0.15 \mathrm{~m} / \mathrm{s} . . .0 .18 \mathrm{~m} / \mathrm{s}$ is sufficient from the laminar diffuser array, provided that the size of the diffuser array is appropriate. The air velocity in the occupied area is limited at $0.4 \mathrm{~m} / \mathrm{s}$ because higher rates may cause the impingement on the wound site and therefore higher infection rates (Salvati et al., 1982).

The chosen solution for ensuring a flow of the inlet air jet as close as possible to the laminar theoretical model, is based on a diffuser with double-equal strength distributor. The ventilation system proposed in this paper generates a hybrid air flow (laminar flow in the area of the operating table and turbulent flow in the rest of the room), very attractive in terms of investment and operating costs.

\section{MATERIALS AND METHODS}

The solution presented in this paper refers to an inlet device with double exponential profile distributor, in order to ensure a flow of the inlet air jet as close as possible to the theoretical model of free isothermal jet (Popovici et al., 2010; Domnita, 2003).

For this purpose, in the Laboratory of Ventilation and Air Conditioning from Technical University of Cluj-Napoca, is designed and built an experimental stand (Fig.1) for measurement of air velocity field of a double-equal strength (double exponential profile) diffuser for spatial air-distribution (Domnita, 2003).

The double-equal strength diffuser consists of the following elements:

A- simple-equal strength (simple exponential profile) distributor, size: $500 \mathrm{~mm} \times 1800 \mathrm{~mm}$, fitted with adjustable blades to produce a uniform air distribution throughout the discharge plane;

B-rectangularconnectingductwith internalairflow stabilization blades, size: $300 \mathrm{mmx} 1800 \mathrm{~mm}$, to achieve a plane-parallel airflow;

C- simple-equal strength distributor, size: $300 \mathrm{~mm} \times 1800 \mathrm{~mm}$, to assure stationary planeparallel airflow in the upstream section;

D- rectangular diffuser, size: $900 \times 1800 \mathrm{~mm}$, to provide a spatial distribution of air in the room.

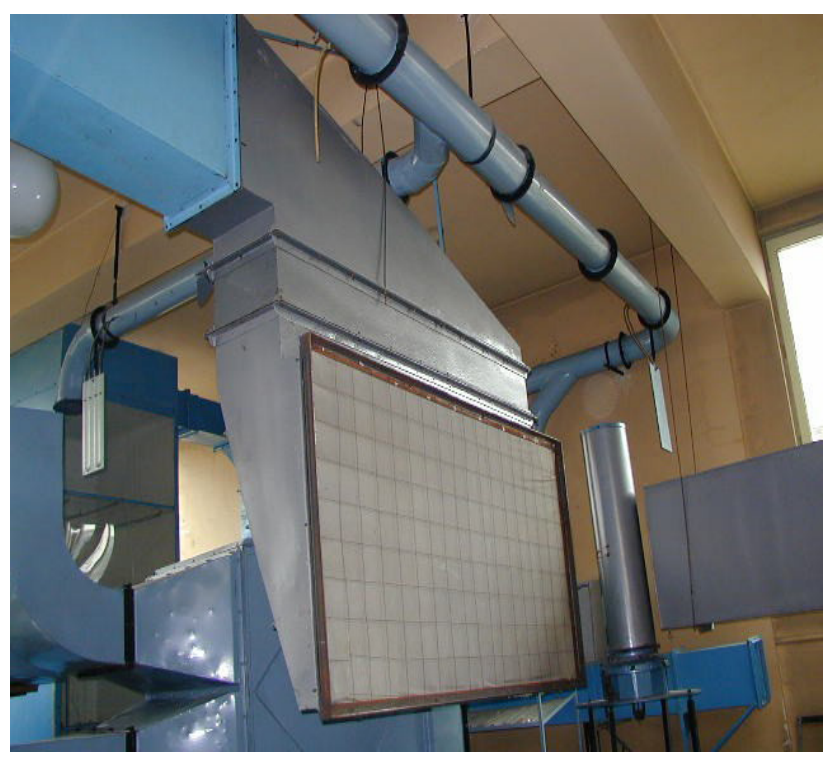

Fig. 1. Inlet device with double-equal strength (double-exponential profile) for spatial air distribution. 
The double-equal strength diffuser was designed by applying twice (for horizontal and for vertical distribution) the equations which allow to calculate the dimensions of the two distributors (A and C) with variable section (Niculescu et al., 1982). For designing this distributors it was used the model with variable width $\mathrm{a}_{\mathrm{x}}$ (Fig. 2). The inlet section is $\mathrm{a}_{\mathrm{o}} \mathrm{xb}$ (width $\mathrm{x}$ height) and the outlet section is $\mathrm{l} \times \mathrm{x}$ (length $\mathrm{x}$ height).

The variable width $\mathrm{a}_{\mathrm{x}}$ is calculated (Niculescu et al., 1982) by using Eq.(1) or the simplified version, Eq.(2):

$$
\begin{aligned}
& a_{x}=\left(\frac{a_{0}}{\ell} e^{\frac{2 \ell}{4 b}}+\frac{\lambda}{4} \int_{x}^{\ell} e^{\frac{2 x}{4 b}} \frac{d x}{x}\right) x e^{-\frac{2 x}{4 b}} \\
& a_{x}=A \cdot a_{0}+B \cdot b
\end{aligned}
$$

A and B can be calculated with Eq.(3):

$$
A=\bar{x} e^{\frac{\lambda \ell}{4 b}(1-\bar{x})} ; B=\frac{\lambda \ell}{4 b} \bar{x} e^{-\frac{\lambda \ell}{4 b} \bar{x}} \int_{\bar{x}}^{\ell} e^{\frac{\lambda \ell}{4 b} \bar{x}} \cdot \frac{d \bar{x}}{\bar{x}}
$$

With $\bar{x}=\frac{x}{\ell}$ is noted the dimensionless distance from $^{\ell}$ the distributor end to the variable width calculation section. The values of $\mathrm{A}$ and $\mathrm{B}$ are given in the literature for $\bar{x}=0 ; 0.1 ; 0.2 ; 0.3 ; \ldots 0.9 ; 1$ and for different values of dimensionless coefficient $\alpha=\frac{\lambda \ell}{4 b}$
(Niculescu et al., 1982).

The friction coefficient $\lambda$ is calculated with Colebrook-White formula for stable turbulent flow (Jagadeesh et al., 2007):

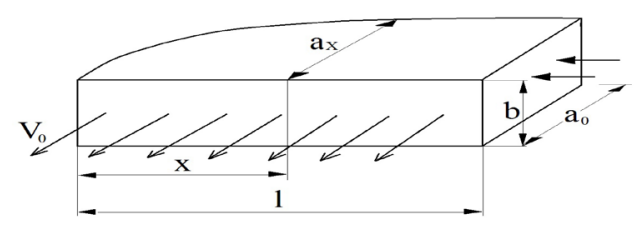

Fig. 2. Simple-equal strength distributor.

$$
\frac{1}{\sqrt{\lambda}}=4 \lg \left(\frac{1,551}{\operatorname{Re} \sqrt{\lambda}}+\frac{\varepsilon}{3,7 d}\right)
$$

Where:

Re - Reynolds invariant,

$\mathrm{d}$ - equivalent diameter of the rectangular inlet section,

$\varepsilon$ - absolute roughness of the distributor.

All diffusers intend to supply air into the occupied area at values for velocity, temperature, humidity, concentrations of different pollutants that correspond to the comfort conditions inside the room. These considerations lead to the value of the initial velocity in the discharge plane, noted with $\mathrm{v}_{0}$. To ensure the uniformity of ventilation, the air velocity is advisable to be as close as possible to a constant value all over the discharge plane. Thus, the initial velocity $\mathrm{v}_{0}$ in the discharge plan of the diffuser is constantly around $0.75 \mathrm{~m} / \mathrm{s}$, a value which corresponds to an easy physical activity. The air jet develops into a free space, which is not influenced by any disturbance surfaces or objects, so the measurements were not affected.

The investigation of the air velocity field of the double-equal strength diffuser involves measuring the values of air velocity with an apparatus that does not influence the course of the current lines through both specialized transducer dimensions and the manner of making measurements (Linden et al., 2000). The airflow measurement device is a digital thermo-anemometer TESTO 435-4 type AIRFLOW, with high accuracy class $( \pm 0.01 \mathrm{~m} / \mathrm{s})$ and measurement range of air velocities from 0 m/s to $20 \mathrm{~m} / \mathrm{s}$ (Fig. 3).

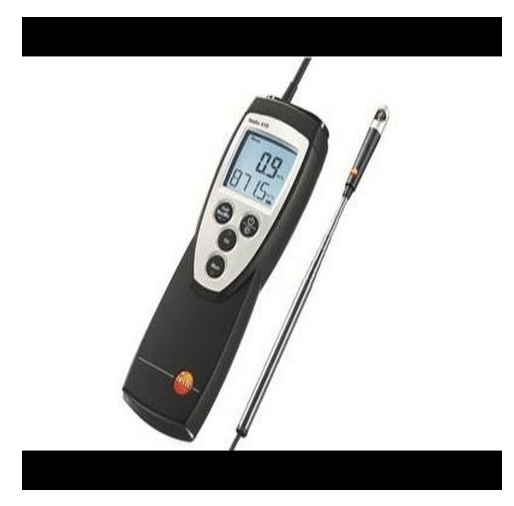

Fig. 3. Digital thermo-anemometer TESTO 435-4 - AIRFLOW. 
There were performed a sufficient number of measurements, with enough equipment accuracy, to provide accurate values of air velocity into the air jet streams (Linden et al., 2000).

To measure the air velocities along the jet, in perpendicular planes to the jet axis, at different distances (noted with $\mathrm{x}$ ) from the discharge plane, is using a classical method that uses, for keeping the same measurement points along the jet, a roller grid with dimensions of $3000 \times 1500 \mathrm{~mm}$ with $100 \times 100 \mathrm{~mm}$ square mesh (Linden et al., 2000).

The measuring grid was placed successively at predetermined distances from the plane of discharge, beginning with the distance $\mathrm{x}=0 \mathrm{~m}$ (discharge plane) and finishing at the distance where axial air velocity was $0.25 \mathrm{~m} / \mathrm{s}$.

\section{RESULTS AND DISCUSSION}

\section{A. Air movement measurements and processing results}

Measured velocities were noted in all the nodes of the grid, (Domnita, 2003, Linden et al., 2000) resulting the air isokinetic curves in six perpendicular planes, at dimensionless distances:

$\bar{x}=0, \bar{x}=1, \bar{x}=2, \bar{x}=4, \bar{x}=6$ and $\bar{x}=8$

(two of which are shown in Fig. 4 and Fig. 5).

The expression of dimensionless distances is

$$
\bar{x}=\frac{x}{d_{o}}, \text { where } d_{o}=\frac{2 \cdot a \cdot b}{a+b}
$$

is the equivalent diameter of the rectangular inlet device with dimensions $\mathrm{a}=900 \mathrm{~mm}$ and $\mathrm{b}=$ $1800 \mathrm{~mm}$.
After the air comes out the discharge device, it enters into a stagnant air environment. As the air jet moving mass advances, due to induction, an amount of increasingly higher of stagnant air joins to the moving air. In this way, the initial air jet kinetic energy is gradually consumed, decreasing the speed of air movement (Chen, 1996).

As it can be seen in Fig. 5, the air is introduced into the room with velocities between $0.2 \mathrm{~m} / \mathrm{s}$ and $0.4 \mathrm{~m} / \mathrm{s}$, inside the limits of the human comfort during a medium to high intensity labor as the surgical activities are. This makes the double-equal strength inlet device for spatial airdistribution to be recommended for use in rooms where is necessary to introduce large volumes of conditioned air with relatively low velocities. For this reason, the distributor is suitable, among the others, for veterinary operating rooms.

\section{Air movement simulation and processing results}

ASHRAE Handbook (2013) suggests that the delivery of air from the ceiling, with a downward movement to several exhaust inlets located on opposite walls, is probably the most effective air movement pattern for maintaining the concentration at an acceptable level. It also recommends that the air should be supplied at the ceiling and exhausted or returned air from at least two locations near the floor. Also, the supply diffusers should be of the unidirectional type and high-induction ceiling or side-wall diffusers should be avoided.

However, an alternative technique, computational fluid dynamics (CFD), sometimes known as airflow modeling, has been proven to be very powerful and efficient in research projects

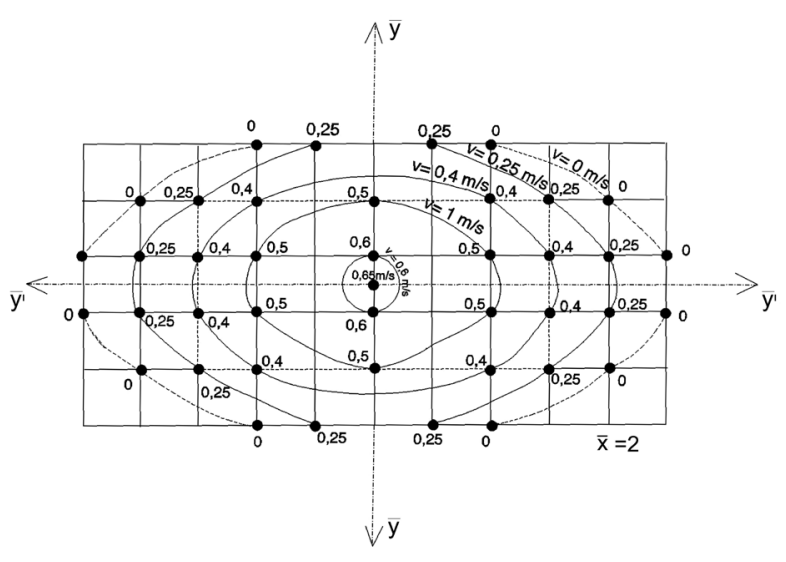

Fig. 4. Isokinetic curves for $\bar{x}=2$.

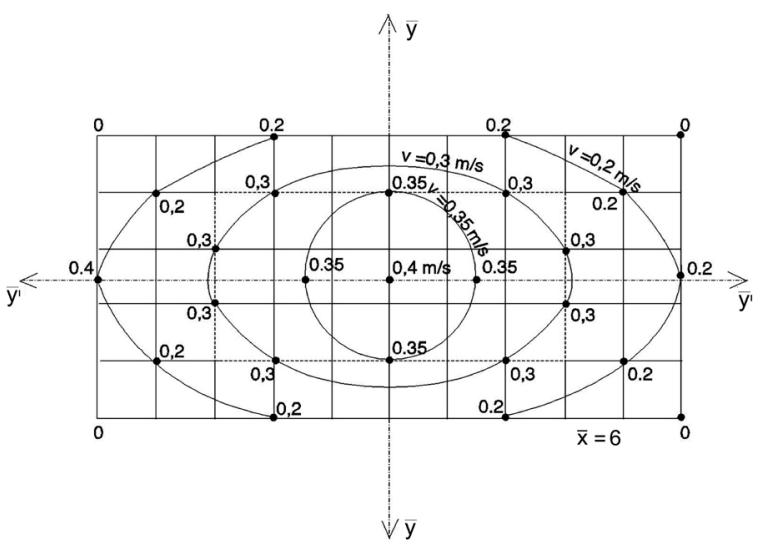

Fig. 5. Isokinetic curves for $\bar{x}=6$. 
involving parametric study on room airflow and contaminant dispersion (Haghighat et al., 1994, Ziang et al., 1995). In addition, the output of the CFD simulation can be presented in many ways, for example, with the useful details of field distributions, as well as overviews on the effects of parameters involved. Therefore, CFD is employed as a main approach in this study.

The paper presents the results of computed air movement simulation for a veterinary cleanroom (standard veterinary operating room) produced by the device described above. Numerical simulations of air movement were made in 3D for a site-model configuration (Fig. 6) by using the computer program I-DEAS 12 . The room meets all constructive and operational criteria suitable for the first group of conventional cleanrooms (operating rooms) and must ensure purity classes of 100,10 or 1 (International Standard ISO 14644$1,2,2015)$.

Supply air is forced through an inlet device GR with double-equal strength diffuser for spatial air distribution, placed in the false ceiling, above the operating table (Fig. 6). The diffuser is rectangular, with dimensions $900 \mathrm{~mm} \times 1800 \mathrm{~mm}$ and the supply air flow rate is $4375 \mathrm{~m}^{3} / \mathrm{h}$. Consequently, the air velocity in the discharge plane of the device is 0.75 $\mathrm{m} / \mathrm{s}$. Both the dimensions and the air velocity are the same as those used for the dimensioning of the device as presented in the first part of the paper.

Exhaust air is sucked through four rectangular grilles GA, located in the lower part of the room at $0.2 \mathrm{~m}$ from the floor (Fig. 6). Exhaust grilles are rectangular, with dimensions $400 \mathrm{~mm} \times 800 \mathrm{~mm}$ and the exhaust air flow rate is $1000 \mathrm{~m}^{3} / \mathrm{h}$ for each of them. The average air velocity in the aspiration plane of the grilles is $0.87 \mathrm{~m} / \mathrm{s}$. The difference between the rate of introduced air and the rate of discharged air is $375 \mathrm{~m}^{3} / \mathrm{h}$ and it comes out of the room due to pressure difference through five overpressure grilles GS located in the bottom of each door.

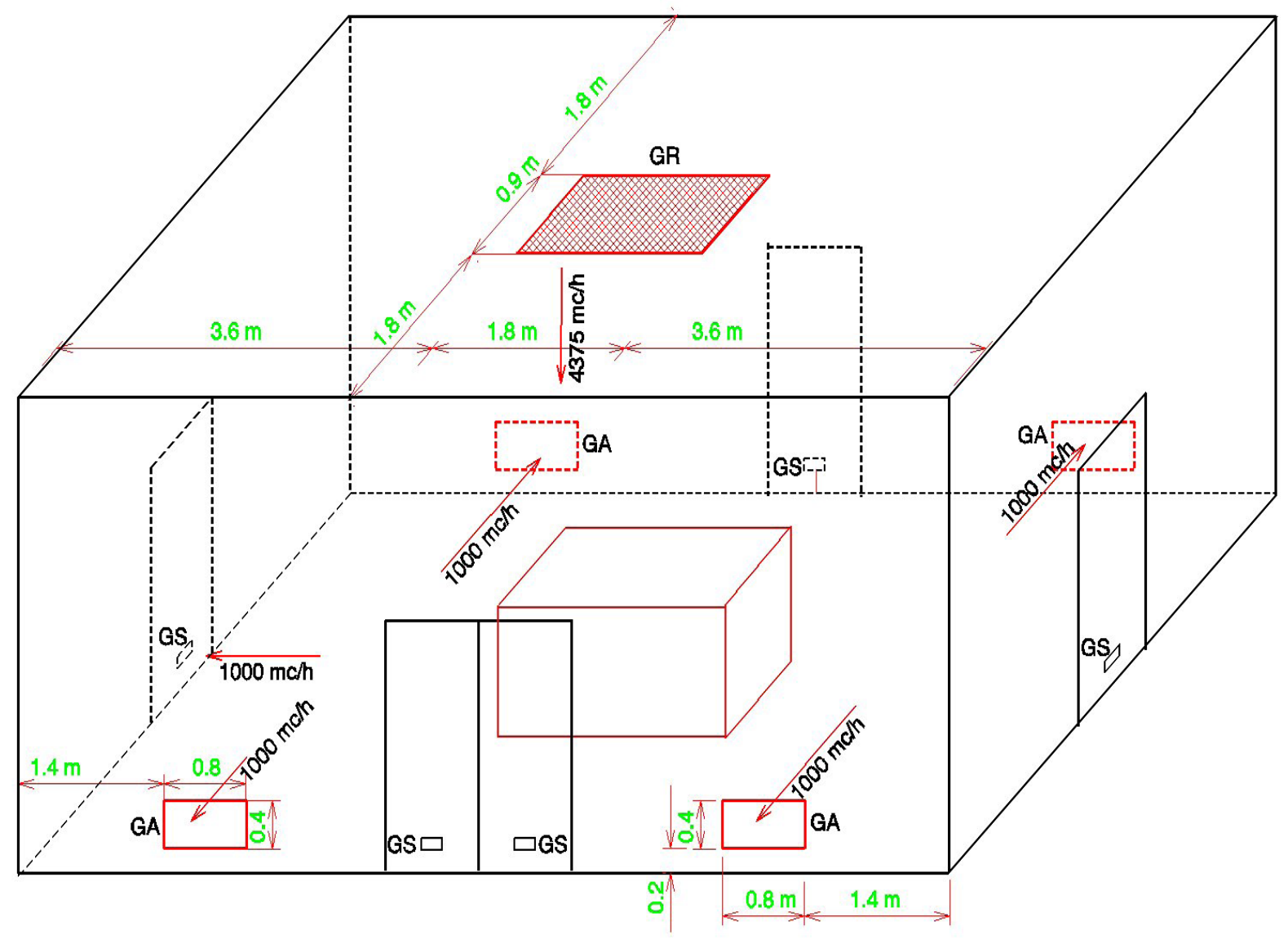

Fig. 6. Site-model configuration of a veterinary operating room. 
The meshing of the model boundary was done using a network of 56,000 tetrahedral finite elements.

Were imposed as input the following:

- Supply air temperature $t_{r}=22^{\circ} \mathrm{C}$;

- Supply air velocity $\mathrm{v}_{\mathrm{r}}=0.75 \mathrm{~m} / \mathrm{s}$;

- Exhaust air temperature $t_{e}=22^{\circ} \mathrm{C}$;

- Exhaust air velocity $\mathrm{v}_{\mathrm{e}}=0.87 \mathrm{~m} / \mathrm{s}$;

- Indoor air temperature $t_{i}=22^{\circ} \mathrm{C}$;

- Bounding surfaces temperature $t_{p}=22^{\circ} \mathrm{C}$;
- Wall roughness $\mathrm{k}=0.4 \mathrm{~mm}$.

The simulations allowed the visualization of velocity and pressure fields of air inside the chamber, under the conditions described above. Numerical simulation case study provides an overview of air velocity and pressure fields generated by an inlet device with double-equal strength diffuser for spatial air distribution, within a sitemodel of a veterinary operating room. Simulation results are displayed graphically by presenting

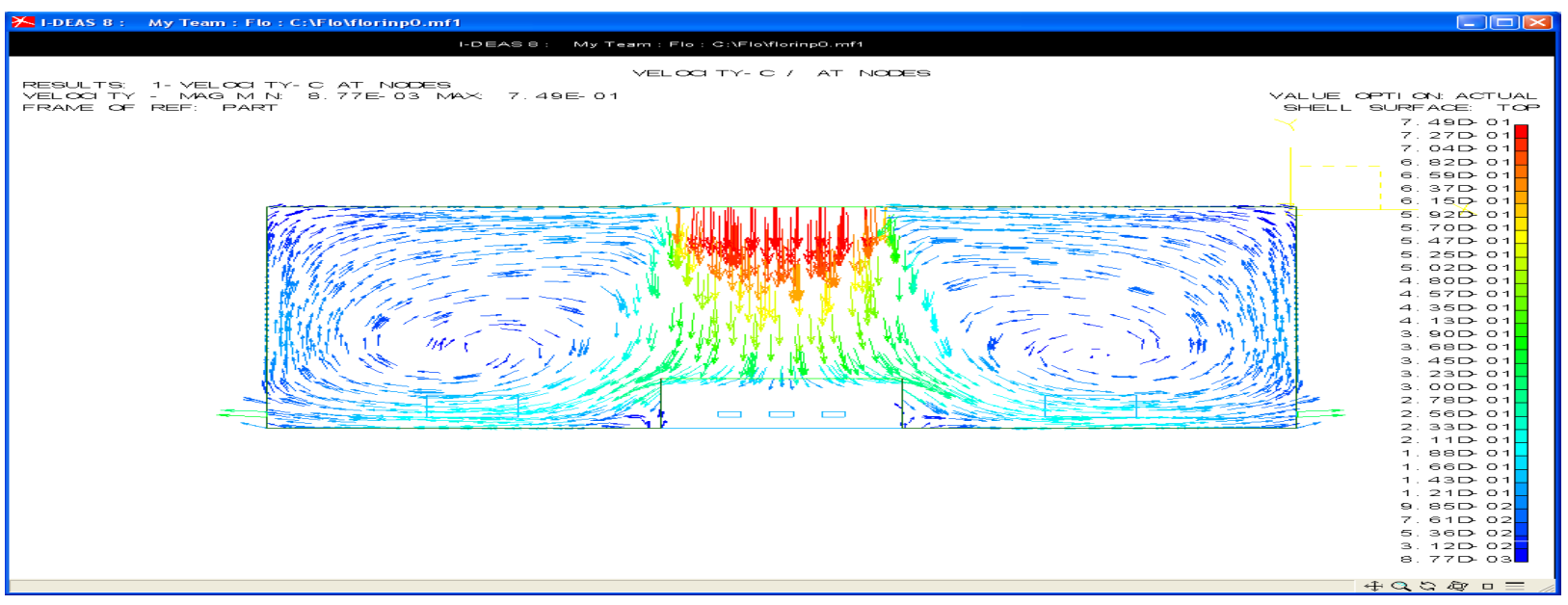

Fig. 7. Air velocity distribution inside the site-model of the veterinary operating room - cross-cut parallel to the longer side.

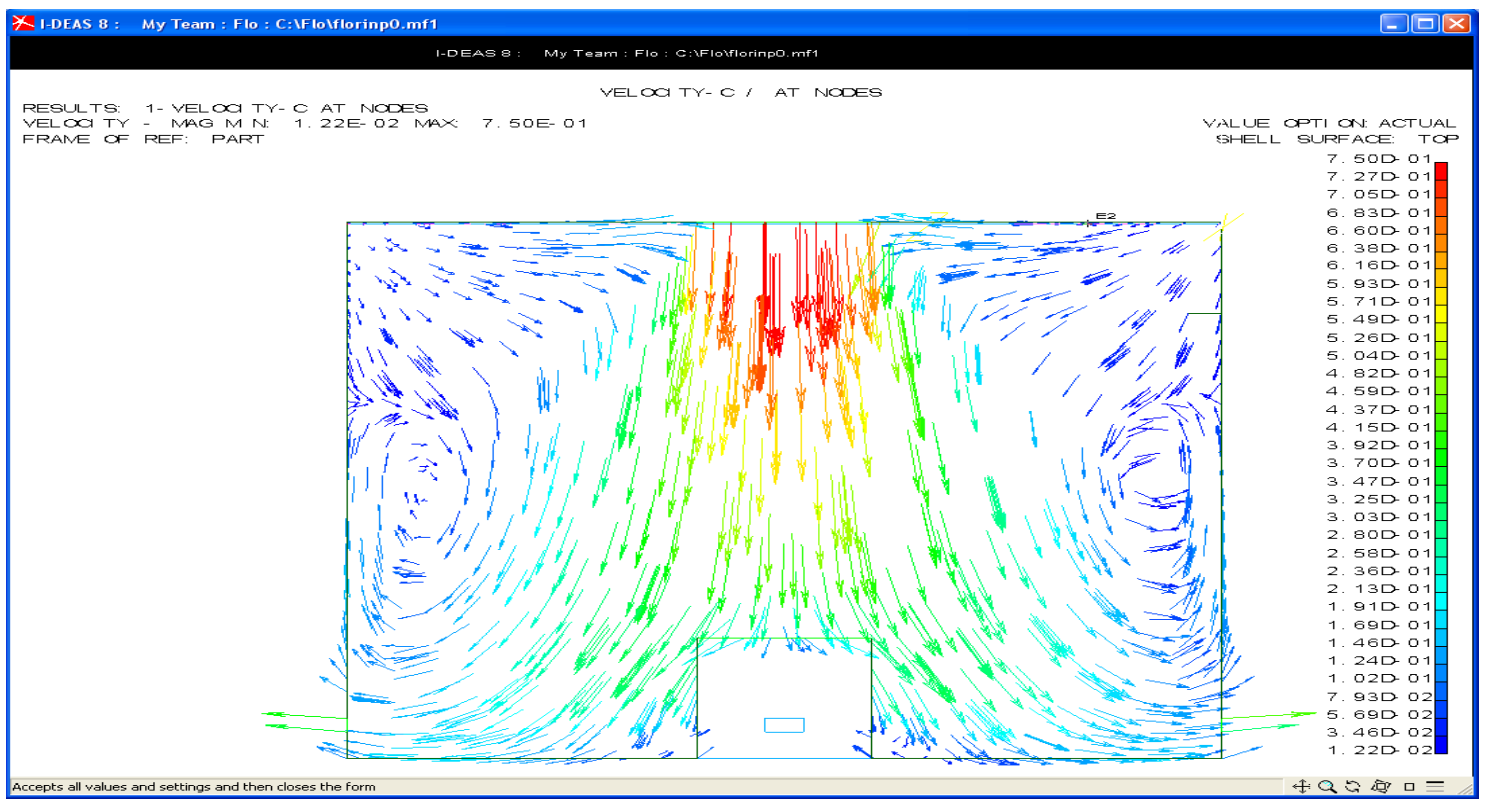

Fig. 8. Air velocity distribution inside the site-model of the veterinary operating room - cross-cut parallel to the smaller side. 
the distribution of air velocity vectors in different planes of intersection with the considered sitemodel configuration. Air velocity vectors are represented with lengths and shades of grey corresponding to the air velocity value of each point considered (Fig. 7 and Fig. 8).

Fig. 7 presents in two-dimensional view the distribution of air velocity inside the sitemodel veterinary operating room, in a cross-cut through the room (parallel to the longer side) that intersects the operating table and the inlet device.

Fig. 8 presents the air velocity distribution inside the veterinary operating room, in a crosscut through the room (parallel to the smaller side) that also intersects the operating table and the inlet device.

The ventilation system proposed by the analyzed model, generates a hybrid air flow (laminar flow in the area of the operating table and turbulent flow in the rest of the room), very attractive in terms of investment and operating costs. In this way, it is obtained a hybrid airflow cleanroom, recommended in recent years in the scientific literature to use in veterinary operating rooms (Hanzawa et al., 2013).

\section{CONCLUSION}

The double-equal strength diffuser (doubleexponential profile) provides relatively uniform air velocities in any perpendicular measurement planes of the air jet stream. Thus, the proposed solution can be used to provide ventilated air in many applications. Also, the large range obtained for air velocities leads to a great flexibility in operations for this kind of devices.

Following the evolutionary stage of inlet air devices, able to achieve enhanced ventilation effects, the designed and executed stand has the some advantages:

- Provides a controlled airflow, close to laminar airflow conditions;

- Provides to the ventilated room an approximately constant air quality, appropriate for indoor environment demanded comfort (International Standard ISO 14644-1,2, 2015);

- Ensures investment, execution and exploitation costs at reasonable values;

- Assures a good opportunity of harmonization with interior design elements (Vilcekova et al., 2015);
- Provides the possibility of directing the air jet, where it requires, towards certain areas that require a greater airflow rate for conditioned air.

Analyzing the results of simulations performed on the model, together with the measurements made in the laboratory on the double-equal strength diffuser, it can be concluded that the device provides good solutions in terms of air flow inside a veterinary operating room. Air movement in the area of the operating table respects the highest requirements in terms of indoor air quality. The rest of the room is fully ventilated and the air velocities are in the limits of human comfort (International Standard ISO 14644-1,2, 2015).

\section{REFERENCES}

1. ASHRAE (2013). ASHRAE Handbook - Applications. American Society of Heating, Refrigerating and AirConditioning Engineers Inc, Atlanta, US, 458-463.

2. Chen $Q$ (1996). Prediction of room air motion by ReynoldsStress models. Building and Environment 31(3):233-244.

3. Domnita FV (2003). Contributions on decontamination and air conditioning in hospitals (in Romanian). Technical University of Cluj-Napoca, Romania, PhD Thesis, 43-44, 66-71.

4. Haghighat F, Jiang Z, Zhang Y (1994). Impact of ventilation rate and partition layout on VOC emission rate: Timedependent contaminant removal. International Journal of Indoor Air Quality and Climate 4:276-283.

5. Hanzawa H, Melikow AK (2013). Airflow characteristics in the occupied zone of ventilated spaces. ASHRAE Transactions 102:79-80.

6. International Standard ISO 14644-1,2 (2015). Cleanroom and associated controlled environments, 7-10, 18-24, 4648.

7. Jagadeesh RS, Chetan CG (2007). Reformulation of the Colebrook-White Equation for Turbulent Flow Friction Factor Calculation. Journal of Industrial and Engineering Chemical Research 46(8):2593-2600.

8. Lidwell OM, Elson RA, Lowbury EJ (1987). Ultraclean air and antibiotics for prevention of postoperative infections. Acta Orthop Scand 58(1):4-13.

9. Linden E, Sandberg M (2000). Temperature and Velocity Measurements of a Diffuser for Displacement Ventilation with Whole-Field Methods. Proceedings of International Conference on Air Distribution in Rooms - Stockholm 1:491-496.

10. Memarzadeh F (2002). Ventilation design handbook on animal research facilities using static microisolators. Bethesda Publishing House, National Institutes of Health, Bethesda, Md, US, 265-268.

11. Niculescu N, Stoenescu P, Duță G, Colda I (1982). Ventilation and Air Conditioning Systems (in Romanian). Didactic and Pedagogic Publishing House, Bucharest, Romania, 225-231. 
12. Popovici T, Domniţa F, Hoțupan A (2010). Ventilation and Air Conditioning Systems (in Romanian). U.T. PRESS Publishing House, Cluj-Napoca, Romania, 1:13-25, 123137.

13. Salvati EA, Robinson RP, Zeno SM, Koslin BL, Brause BD, Wilson PD (1982). Infection rates after 3175 total hip and total knee replacements performed with and without a horizontal unidirectional filtered air- flow system. Journal of Bone and Joint Surgery 64A(4):525-535.
14. Vilcekova S, Burdova EK (2015). Multi-criteria analysis of building environmental assessment regarding building materials and structures. Proceedings of International Multidisciplinary Scientific GeoConference Surveying Geology and Mining Ecology Management - SGEM 1(5):557-564.

15. Ziang Z, Chen Q Haghighat F (1995). Airflow and air quality in large enclosures. ASME Journal of Solar Energy Engineering 117:114-122. 